\title{
Commercial in confidence: public health without confidence
}

\section{Implementing public health measures with obvious benefits becomes a complex struggle when commercial interests are paramount}

T he evening of 25 March 2009 was cool for the community consultation - a necessary step before the implementation of fluoridation of the Cobram water supply. There were only a few people present in the Civic Centre, but they warmly applauded the initiative. None of the expected antifluoride lobby turned up, and the meeting was a short one...

After all, it is accepted that fluoridation of drinking water is an effective way to ensure the whole community can benefit from fluoride's preventive role in reducing tooth decay. ${ }^{1,2}$

Thus, it was expected that Cobram would follow the path of nearby Yarrawonga and this seemingly routine adoption of a well researched public health measure would be quickly achieved.

Wrong! Over 5 years later, Cobram still has not had its water supply fluoridated.

\section{The story so far}

Cobram, a small country town on the Murray River in Northern Victoria, is where the Murray Goulburn Cooperative, one of the largest milk producers in Victoria, has existed since 1949. In 1951, the Co-operative diversified into cheesemaking. It is a major contributor to the local economy. In early 2014, the company announced that it would build a $\$ 74$ million "world class cheese cut-and-wrap facility" in Cobram to serve Australian and Asian markets and, as part of a broader \$38 million investment, it would increase the Cobram factory's capacity to produce infant nutrition products - some for export. ${ }^{3}$

The reason for the inaction over water fluoridation? Murray Goulburn did not want fluoridated water in their milk products, including the infant formula preparations. This was not disclosed in any of the formal community discussions, and only came to light when the Department of Health enquired about the cause for the delay in fluoridation. It seemed that commercial considerations regarding fluoridation simply outweighed community dental health.

Although, perhaps it was not that simple. There were other options - one being whether the government was prepared to fund a separate water pipeline for the Co-operative's use. The company argued that the options of either precipitating the fluoride out

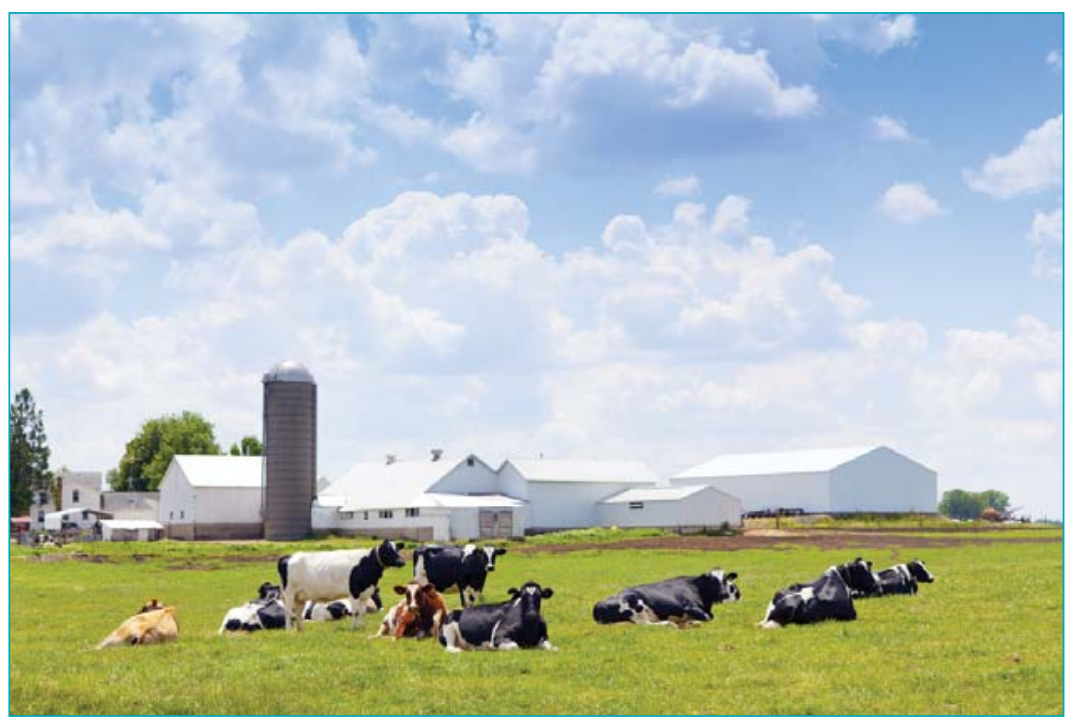

during the manufacturing processes or treating the factory water supply to remove fluoride were less cost-effective.

The possibility that fluoridation might not affect the product was not considered. One can only suspect that commercial motives were paramount. Asian countries are a large importer of dairy products, and these countries are, by and large, averse to fluoridated water. China has no fluoridation ${ }^{4}$ and Japan, almost none.

\section{"Fluoridation policy is in danger of degenerating into public health anarchy"}

There is concern about dental fluorosis, but there is little evidence to suggest that fluoridated water, particularly in infant formulas, causes significant fluorosis. ${ }^{5}$ A significant number of the infant formulas sold in Australia are imported, ${ }^{6}$ but these have sufficiently low levels of fluoride for the Australian Research Centre for Population Oral Health and state health departments to deem them safe for reconstitution using water within the target range for fluoridation $(0.6-1.1 \mathrm{mg} / \mathrm{L})$. So, what is the fuss about?

Companies do not engage in public health debate about fluoridation. In fact, one international company that sells products on the Australian market refuses to indicate where its factories are; it does, however, admit that its products use unfluoridated water. The degree of secrecy about these matters can lead to comments layered with conjecture.

AO, MDBS, PhD, DSc(Hon) Melbourne, VIC.

jbbest@iimetro.com.au

doi: 10.5694/mjal5.00050
In November last year, just before the Victorian state election, the member for Murray Valley finally announced a \$4.1 million project including, inter alia, a 
$2.5 \mathrm{~km}$ pipeline carrying unfluoridated water from the Cobram water treatment plant to the Murray Goulburn dairy processing plant. ${ }^{7}$ The Co-operative agreed to make a contribution to the funding, and the project was expected to be completed in 2016.

\section{The cost of living in a small community}

This was a win-win situation for Cobram and the Cooperative, with most of the funding coming from the government.

But is it such a win? Cobram, and in particular its children, will have missed out for 7 years on fluoridated water. For the community at large, the Cobram imbroglio barely raised a policy ripple. Small communities of less than 1000 may miss out on fluoridation altogether because it is not regarded as cost-effective. However, these dismissed populations add up to 2 million people nationwide. ${ }^{8}$

The question, then, becomes one of assessing the effectiveness of advocacy when any proposed change is confronted by the fear, real or otherwise, of losing jobs. However, when advocacy becomes ineffective, change has to be achieved by subtler nagging of government, because there is virtually no sensible person who would disagree about the benefits of fluoride. ${ }^{9}$

\section{Have we lost the plot?}

It is all about cost; especially, as with all public health and commercial considerations, there is a further twist - in this case, the increase in the consumption of bottled water, almost all of which is suboptimally fluoridated. Bottled water is permitted to have the same level of fluoride recommended for drinking water - 0.6-1.1 mg of fluoride per litre. Since its introduction in the 1980s, bottled water has grown into a $\$ 500$ million a year industry in Australia and has become the main source of drinking water in one in 10 households. However, as the chair of the Australian Dental Association's Oral Health Committee said, "people who prefer bottled water ... risk putting their dental health back to the 1960s, when tooth decay was widespread because there was no fluoride in the water".10

The rise in bottled water production without any serious move by the multinational manufacturers towards fluoridation is presumably one of those awkward commercial-in-confidence matters. Without concerted nagging of the policymakers, such as occurred in Cobram, nothing happens.

In fact, fluoridation in Australia has gone backwards. In Queensland, where once it was obligatory, legislation has made it a voluntary responsibility. Many local governments have subjugated public health to the commercial imperative of it being "too costly", despite evidence to the contrary. ${ }^{11}$
Fluoridation policy is in danger of degenerating into public health anarchy where commercial interests can shelter behind the mantra of freedom of choice with its rehearsed arguments of blind libertarianism, no matter how obvious the public good. Presumably none of these libertarians would want to advocate freedom of choice about a clean water supply.

Ignoring the bleeding obvious should not be allowed to make the community bleed the cost of appalling teeth, especially when there are continual complaints about how disadvantaged rural areas are with regard to dental health.

At least, the Cobram community will eventually know better times in dental health; but now, what about the fluoridation of bottled water?

Competing interests: No relevant disclosures.

Provenance: Commissioned; not externally peer reviewed.

References are available online at www.mja.com.au. 
1 National Advisory Committee on Oral Health. Healthy mouths healthy lives. Australia's national oral health plan 2004-2013. Adelaide: Government of South Australia, on behalf of the Australian Health Ministers' Conference, 2004. http://www. adelaide.edu.au/oral-health-promotion/resources/public/ pdf_files/oralhealthplan.pdf (accessed Mar 2015).

2 National Health and Medical Research Council. A systematic review of the efficacy and safety of fluoridation. Canberra: NHMRC, 2007. http://www.nhmrc.gov.au/_files_nhmrc/ publications/attachments/eh41_l.pdf (accessed Mar 2015).

3 Langley S. Murray Goulburn plans $\$ 127$ million in project investments, share restructure. Australian Food News 2014; 7 May. http://ausfoodnews.com.au/2014/05/07/murraygoulburn-plans-127-million-in-project-investments-sharerestructure.html (accessed Mar 2015).

4 American Dental Association. Fluoridation facts. Chicago: ADA, 2005. http://www.ada.org/ /media/ADA/Member\%20 Center/Flles/fluoridation_facts.ashx (accessed Mar 2015).

5 Australian Research Centre for Population Oral Health. The use of fluorides in Australia: guidelines. Guideline 6. Aust Dent J 2006; 51: 195-199. https://www.adelaide.edu.au/arcpoh/ downloads/publications/journal/2006-spencer-aj.pdf (accessed Mar 2015).

6 Food Standards Australia New Zealand. Regulatory impact statement: policy guideline for the regulation of infant formula products. 17 Mar 2011. http://ris.dpmc.gov.au/ files/2011/05/Infant_Formula_Products_RIS.pdf (accessed Mar 2015).

7 McCurdy T. \$3.1 million to support growth at MGC Cobram [media release]. 13 Nov 2014. http://timmccurdy. nationalpartyonline.com/_blog/Press_Releases/post/31million-to-support-growth-at-mgc-cobram (accessed Mar 2015).

8 Cobiac LJ, Vos T. Cost-effectiveness of extending the coverage of water supply fluoridation for the prevention of dental caries in Australia. Community Dent Oral Epidemiol 2012; 40: 369-376.

9 Jones S, Burt BA, Petersen PE, Lennon MA. The effective use of fluorides in public health. Bull World Health Organ 2005; 83 : 670-676.

10 Choice. Is bottled water worth the cost? 8 August 2014. www.choice.com.au/food-and-drink/drinks/water/articles/ bottled-water (accessed Mar 2015).

1 Ciketic S, Hayatbakhsh MR, Doran CM. Drinking water fluoridation in South-east Queensland: a cost-effectiveness evaluation. Health Promot J Austr 2010; 21: 51-56. 